\title{
THE HÆMODYNAMICS OF MITRAL STENOSIS BEFORE AND AFTER COMMISSUROTOMY
}

\author{
BY \\ JANET DICKENS, * LUIZ VILLACA, ASHER WOLDOW, AND HARRY GOLDBERG \\ From the Brith Sholom Cardiopulmonary Laboratory, Department of Medicine, Hahnemann Medical College and Hospital, \\ and The Bailey Thoracic Clinic, Philadelphia, Pennsylvania
}

Received December 6. 1956

Clinical changes following mitral valvotomy are sometimes difficult to evaluate. The need for an objective method in assessing the effectiveness of surgery is apparent, and the value of combined heart catheterization in appraising the hæmodynamics of mitral stenosis has been reported (Goldberg et al., 1955, 1956). A total of 58 patients have been studied by this procedure, 16 of them after as well as before mitral valvotomy. The importance of the combined technique can be readily appreciated, particularly in assessing the changes of pressure gradient and flow across the involved valve. Comparison of the data with those previously obtained by right heart catheterization alone has yielded significant differences and provides additional support for the continued use of this new technique.

\section{MATERIAL AND MethodS}

Sixteen patients, thirteen women and three men, were studied before and after mitral valvotomy. The diagnosis of pure mitral stenosis was confirmed by surgery in all patients. Mitral insufficiency was not produced in any case. Cardiac catheterization was repeated from twelve days to four months after operation.

Combined heart catheterization was performed in the post-absorptive state with premedication consisting of seconal $120 \mathrm{mg}$. and demerol $50 \mathrm{mg}$. Right heart catheterization was done in the usual manner except that the patient was placed in the prone position. After the pulmonary venous capillary pressure was recorded, the catheter was positioned in the right or left pulmonary artery close to the hilus. A Cournand needle then was placed in the brachial artery. Left heart catheterization was performed by the Fisher modification (Kent et al., 1955) of the method originally described by Biörk (1953). Our experiences in 450 cases of left heart catheterization are described elsewhere (Bougas et al., 1956; Musser et al., 1956). With the aid of fluoroscopy, a 6-inch, 18-gauge, thin-walled needle (Becton and Dickinson) was introduced into the left atrium via the eighth or ninth intercostal space $4 \mathrm{~cm}$. from the midline. A polyethylene or nylon catheter was inserted through the needle. Continuous monitoring of the pressure was done on an oscilloscope or poly-oscillograph (Sanborn) as the catheter was advanced into the left ventricle. All manœuvring then was halted until the control cardiac rate, rhythm, and blood pressure were re-established. At this time, expired air was collected in a Tissot spirometer during a 3-min. period, at the middle of which samples were withdrawn from the pulmonary and brachial arteries simultaneously. Pressures were immediately recorded as the catheter was withdrawn from the left ventricle to the left atrium to determine the ventricular filling pressure gradient. In five patients with atrial fibrillation, a second needle was inserted into the left atrium and simultaneous recordings were made from the left ventricle and left atrium during estimation of the cardiac output.

The cardiac output was calculated by the direct Fick method. Blood oxygen was determined according to the method of Van Slyke and Neill (1924). Respiratory analysis was done on the Pauling oxygen analyser. Pressures were measured by electromanometers and recorded on a poly-oscillograph (Sanborn). The zero

* Samuel Kardon Fellow in Cardiovascular Physiology; work done partly during tenure of National Heart Institute Fellowship. 
level was taken as $5 \mathrm{~cm}$. below the angle of Louis. Pressure gradients were measured by planimetric integration. The mitral valve area and pulmonary vascular resistance were calculated by a modification of the formulæ of Gorlin and Gorlin (1951), and right ventricular work was calculated as originally described (Gorlin, 1951).

$$
\text { Mitral valve area, M.V.A. }\left(\mathrm{cm}^{2}\right)=\frac{\text { M.V.F. }}{31 \sqrt{\text { V.F.G. }}}
$$

where M.V.F. (ml./V.F.P. sec.)=C.O. (ml./min.)/V.F.P. $\times$ H.R.

and V.F.G. $(\mathrm{mm} . \mathrm{Hg})=$ L.A.v.f.p. - L.V.v.f.p.

Pulmonary Vascular Resistance, P.V.R. (dynes sec. $\left.\mathrm{cm}^{-5}\right)=($ P.A.m - L.A.m $) \times 1332 /$ C.O. $(\mathrm{ml} . / \mathrm{sec}$.)

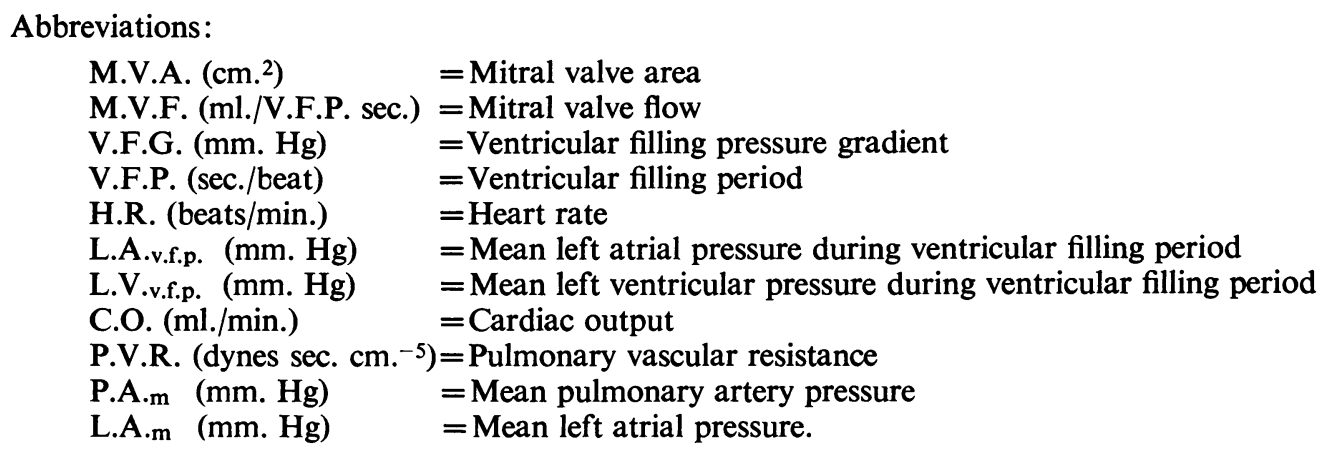

\section{RESULTS}

Before Operation. Mitral valve flow was generally low, ranging from 59 to $190 \mathrm{ml}$./V.F.P. sec. (Table I). The flow was considered below normal (Goldberg et al., 1956) (150 ml./V.F.P. sec.) in ten of the thirteen patients in whom it could be calculated before operation. It was less than $100 \mathrm{ml}$./V.F.P. sec. in four patients. The ventricular filling pressure gradient (V.F.G.) which was constantly observed, ranged from 5 to $26 \mathrm{~mm}$. Hg. The mitral valve area was reduced in all patients, ranging from 0.5 to $1.3 \mathrm{~cm} .^{2}$

The mean left atrial pressures were raised, ranging from 10 to $30 \mathrm{~mm}$. In eight patients the left atrial pressure was greater than $20 \mathrm{~mm}$. $\mathrm{Hg}$. The pulmonary capillary pressures were above the upper limits of normal $(12 \mathrm{~mm} . \mathrm{Hg})$ in eleven of the fifteen patients in whom this value was obtained, ranging between 10 and $32 \mathrm{~mm}$. There was generally good agreement between the left atrial and capillary pressure tracings in both contour and magnitude. The end-diastolic pressure in the left ventricle was within normal limits (less than $10 \mathrm{~mm} . \mathrm{Hg}$ ) in all but one case, in which it was $12 \mathrm{~mm}$. $\mathrm{Hg}$.

The cardiac index was generally low, averaging $2 \cdot 11 . / \mathrm{min} . / \mathrm{M}^{2} \mathrm{BS}$ (range: 1.4 to $4.51 . / \mathrm{min} . / \mathrm{M}^{2} \mathrm{BS}$ ). In the patients in whom this value was reduced, the arteriovenous oxygen difference was increased.

The mean pulmonary artery pressure was raised in all but three patients: the rise was mild $(20-25 \mathrm{~mm} . \mathrm{Hg})$ in two, moderate $(26-39 \mathrm{~mm} . \mathrm{Hg})$ in five, and severe (greater than $40 \mathrm{~mm} . \mathrm{Hg})$ in six patients. The effective work of the right ventricle was increased in seven (greater than 1.0 $\mathrm{kgM} / \mathrm{min}$.) and within normal limits in six patients.

After Operation. (1) Results Based on Response of Pressure Gradient and Mitral Valve Flow. (a) Nine patients showed a significant fall in pressure gradient accompanied by a significant increase in flow, indicating improvement following surgery (Cases 1-9) (Table I) (Fig. 1). The mitral valve area increased in every case, ranging from 0.5 to $1.2 \mathrm{~cm} .{ }^{2}$ before and from 1.8 to $4.3 \mathrm{~cm} .{ }^{2}$ after operation. The mitral valve flow ranged from 59 to $150 \mathrm{ml}$./V.F.P. sec. before and from 155 to $304 \mathrm{ml}$./V.F.P. sec. after operation, increasing significantly in all patients.

The ventricular filling pressure gradient ranged from 11 to $26 \mathrm{~mm}$. $\mathrm{Hg}$ before and from 3 to $13 \mathrm{~mm}$. after operation. In eight patients in this group in whom the left atrial pressure fell significantly, the left ventricular end-diastolic pressure fell in three, remained unchanged in one, and rose 

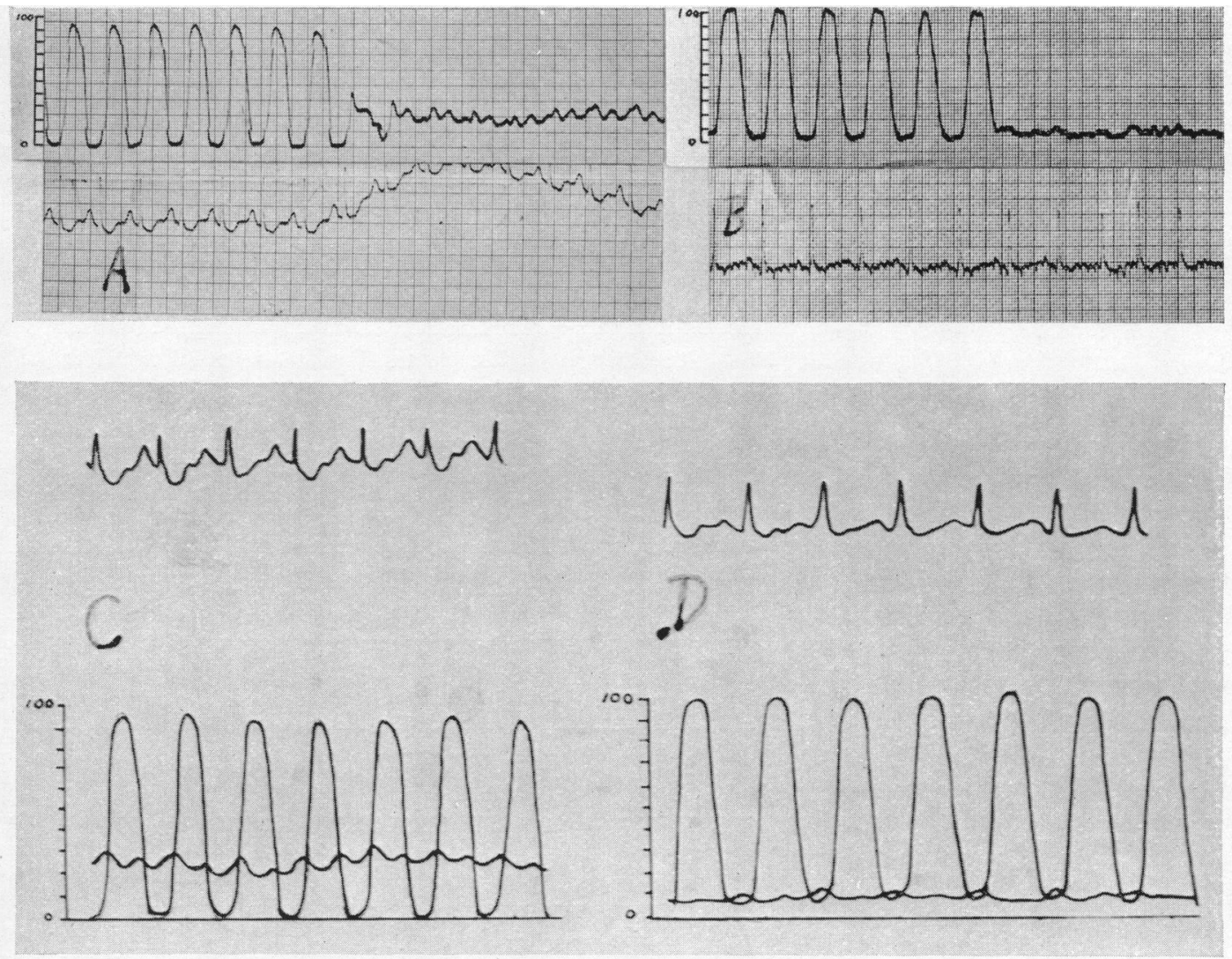

Fig. 1.-Case 8. Above. Continuous pressures recorded from the left ventricle to the left atrium (above), and electrocardiogram (below). (A) Before and (B) after mitral valvotomy. Note lower left atrial pressure. Below. Left atrial and left ventricular pressure tracings redrawn and superimposed, showing ventricular-filling pressure gradient. (C) Before and (D) after mitral valvotomy. Note decrease in pressure gradient. M.V.A. increased from 0.08 to $3.6 \mathrm{~cm}^{2}$.

slightly $(2-5 \mathrm{~mm} . \mathrm{Hg})$ in four. In one patient in whom the left atrial pressure was unchanged and remained within normal limits, the left ventricular end-diastolic pressure was increased from 0 to $9 \mathrm{~mm}$. Hg.

Eight patients of this group had normal sinus rhythm. Before operation, the predominant wave in the left atrial tracing was the $a$ wave in six patients and ranged from 21 to $48 \mathrm{~mm}$. in height. The $a$ and $v$ waves were of equal prominence in the other two patients. After operation, the $a$ waves decreased in all, ranging from 10 to $22 \mathrm{~mm}$. in height. The $a$ and $v$ waves were of approximately equal magnitude in five cases while, in the remaining three, the $a$ wave was still predominant.

In the eight patients with normal sinus rhythm, the ventricular filling period per beat ranged from 0.24 to $0.38 \mathrm{sec}$., averaging $0.30 \mathrm{sec}$. before, and from 0.16 to $0.27 \mathrm{sec}$., averaging $0.21 \mathrm{sec}$. after operation. The filling period decreased in six patients, in whom the cardiac rate at the time of the post-operative study was unchanged in three, increased in two, and decreased in one. The filling period was unchanged in the remaining two patients.

The cardiac index was below normal in all but one of the patients in this group, rising after operation in eight and to within normal limits in seven of them. In one, there was no change. The arteriovenous oxygen difference decreased after operation by at least 1 vol. per $100 \mathrm{ml}$. in all but two patients, in one of which the cardiac index had increased only slightly.

The mean pulmonary artery pressure varied considerably before operation and fell significantly 


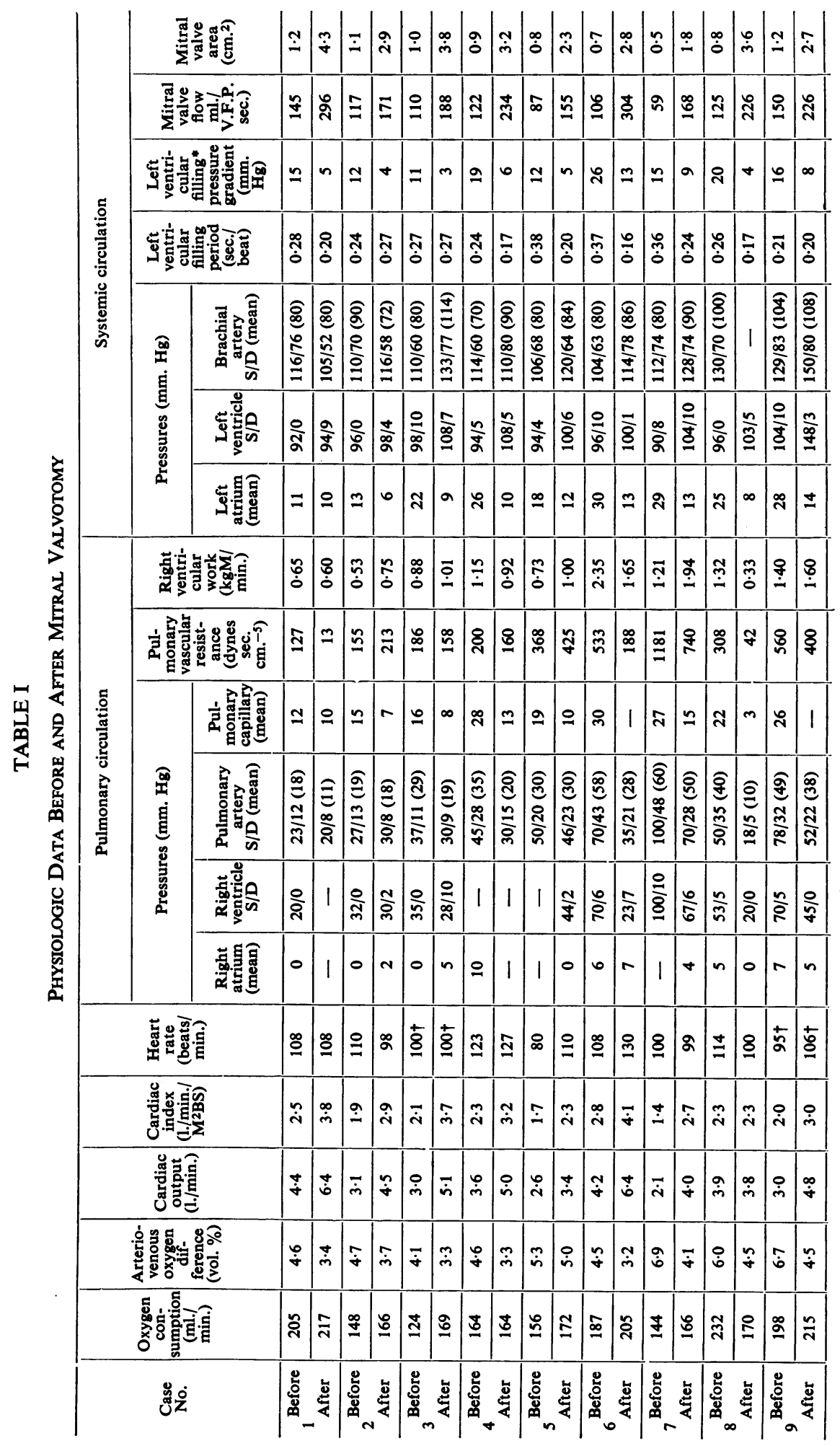




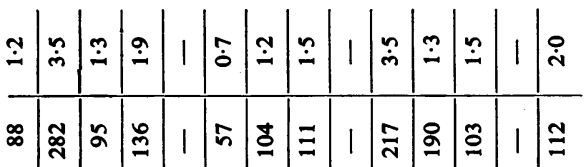

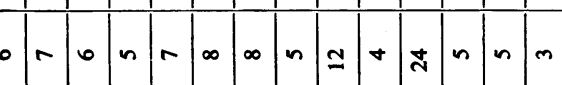

గ్రิ

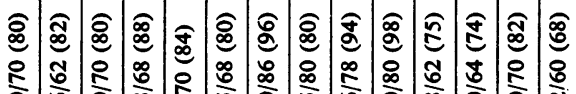

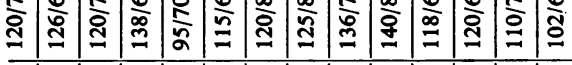

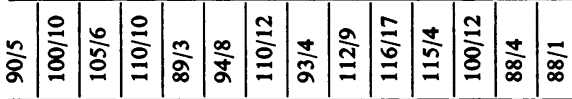

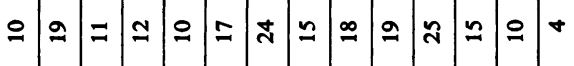

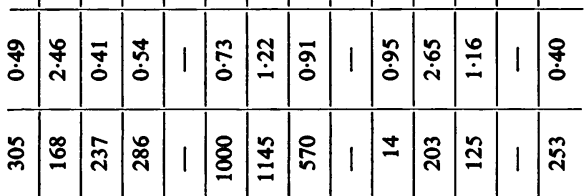

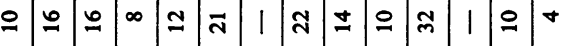

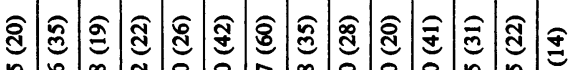

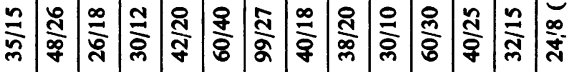

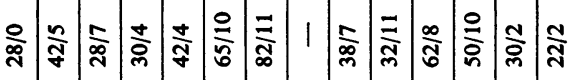

\begin{tabular}{|c|c|c|c|c|c|c|c|c|c|}
\hline & 0 & $n$ & $n$ & $\simeq 0$ & $a+$ & - & +1 & & $\omega$ \\
\hline$z$ & t. & $\stackrel{\vdots}{\Xi}$ & t) & 志节 & 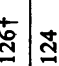 & & $\stackrel{\infty}{=}$ & & 㕝 \\
\hline & 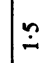 & $\Xi$ & 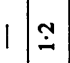 & \pm & $\stackrel{-\infty}{-} \mid$ & $m$ & $\because$ & & $\dot{\mathrm{d}}$ \\
\hline & $\hat{\dot{\sim}}$ & 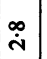 & $1 \mid \stackrel{\dot{\sim}}{ }$ & $\dot{\sim}$ & $\underset{\dot{\sim}}{\infty} \mid$ & 号 & : & & $\tilde{m}$ \\
\hline & $\infty$ & $\overrightarrow{\dot{\omega}}$ & $\dot{\phi} \dot{\dot{\phi}}$ & & \begin{tabular}{l|l} 
& 1
\end{tabular} & $\stackrel{i}{i}$ & $\stackrel{\dot{m}}{+}$ & & $\ddot{n}$ \\
\hline & $\stackrel{\Xi}{\Phi}$ & $\Xi$ & $\stackrel{2}{\beth}$ & $\stackrel{\infty}{\Xi}$ & 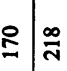 & $\stackrel{0}{N}$ & & & $\underline{\Xi}$ \\
\hline & & & & & & & & & \\
\hline
\end{tabular}

을

N

N

암

응

$\stackrel{9}{+}$

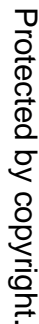


in four, moderately in one, and slightly in one. It remained essentially unchanged in three. Although the pulmonary vascular resistance fell significantly in four patients, it remained above normal in two of these. In one patient with a raised resistance before operation, there was no significant change. In those in whom the resistance was within normal limits before operation, it remained so afterwards.

In five patients, the right ventricular work was above $1.0 \mathrm{kgM} / \mathrm{min}$. before operation: in three it fell significantly, in two to within normal limits. After operation it was greater than $1.0 \mathrm{kgM} / \mathrm{min}$. in three patients; the mitral valve flow in these three had increased considerably following surgery, contributing in part to the increased work of the right ventricle.

(b) Two patients showed an increase in mitral valve flow with little change in pressure gradient. Possibly Case 10 improved since there was a large increase in the mitral valve flow with no increase in pressure gradient. The increase in cardiac output was accompanied by a fall in arteriovenous oxygen difference. The large increase in flow was probably responsible for the rise in the left ventricular end-diastolic pressure, left atrial, and pulmonary artery pressures, and right ventricular work. The data on Case 11 probably reflect little improvement physiologically at this time: there was no change in pressure gradient and only a moderate increase in mitral valve flow with consequent little change in mitral valve area; the arteriovenous oxygen difference was unchanged as were the left atrial and pulmonary artery pressures.

(c) Case 13 showed little change in mitral valve flow, pressure gradient, and mitral valve area. Right heart catheterization data in this patient did not reflect the poor response, and the mechanism of the fall in pulmonary artery pressure in this case is not clear.

(d) Three patients must be considered individually since their pre-operative data were not complete. In Case 14 the mitral valve flow and area after operation were well within normal limits, while the filling pressure gradient, obtained before and after operation, fell significantly, and the mean pulmonary artery pressure decreased slightly. The data, although incomplete, suggest improvement following surgery.

The data obtained in Case 12 indicate a poor result. The pressure gradient was unchanged after operation. The mitral valve flow was much reduced from the normal value while the arteriovenous oxygen difference was higher; and the mean left atrial and pulmonary artery pressures rose. The response of Case 16 is difficult to evaluate without a knowledge of the mitral valve flow before operation. The calculated mitral valve area appeared adequate although after operation the mitral valve flow was low and the pressure gradient changed little: the mean pulmonary artery and left atrial pressures fell.

(e) In Case 15 both mitral valve flow and ventricular filling pressure gradient decreased significantly. The slight change in area precludes the assumption of improvement in this patient, but the mean left atrial and pulmonary artery pressures fell as well as the pulmonary vascular resistance and right ventricular work.

(2) Results Based on Pulmonary Artery Response Following Surgery. (a) Six of the sixteen patients showed a significant fall in the mean pulmonary artery pressure after operation. Before, the mean pulmonary artery pressure was raised moderately in one $(35 \mathrm{~mm}$. $\mathbf{H g})$, and greatly in five $(40-60 \mathrm{~mm} . \mathrm{Hg})$. Of these six patients, mitral valve area increased significantly in four. These four also showed an excellent response of pressure gradient and flow following surgery: the remaining two (Cases 13 and 15) showed only a slight increase in mitral valve area and equivocal results in terms of pressure gradient and flow. In Case 13 the significance of the fall in the pulmonary artery pressure was questionable in the presence of a decrease in flow after operation.

(b) One patient (Case 9) showed only a moderate fall in the pulmonary artery pressure with an excellent response of gradient and flow after operation. The mitral valve area increased significantly and the left atrial pressure fell.

(c) Three patients showed a slight fall in the pulmonary artery pressure after operation. Although there are too few patients in this group to compare the response of the pulmonary artery pressure with that of gradient and flow, one (Case 3) showed an excellent response of gradient 
and flow with an increase in valve area. Similarly, in Case 14, there was a large fall in the gradient and a normal mitral valve flow after operation. A third (Case 16) in this group showed no change in pressure gradient and still had a low flow.

(d) Three patients had an increase in pulmonary artery pressure after operation. In one (Case 10), the mitral valve area was increased significantly: there was a significant increase in mitral valve flow with no change in the pressure gradient and the mean left atrial pressure also increased. The increase in pulmonary artery pressure probably reflects the increase in flow.

In a second (Case 11), the slight rise in the pulmonary artery pressure from a normal value was accompanied by a moderate increase in the mitral valve flow with little change in the pressure gradient. The mitral valve area, however, was not increased much and the left atrial pressure was unchanged. In the third (Case 12), the pressure gradient was unchanged, but the mitral valve flow obtained only after operation was very low, and the mitral valve area was considered inadequate.

(3) Results Based on Data Before Operation. Analysis of the data based on mitral valve area or pulmonary artery pressure revealed little correlation with the response after operation in mitral valve area, flow, and pressure gradient or pulmonary artery pressure. Of three patients with normal resting pulmonary artery pressures before, two (Cases 2 and 1) showed a significant response of pressure gradient and flow, and an increase in area. One (Case 11) showed a poor response of pressure gradient and mitral valve flow with a slight increase in mitral valve area. Similarly, of six patients with severe pulmonary hypertension, the response of pressure gradient, mitral valve flow and area was excellent in four and poor in one: the sixth (Case 15) could not be assessed because the fall in pulmonary artery pressure was accompanied by a fall in flow.

\section{Discussion}

Before the application of combined heart catheterization to the study of mitral valvular disease, the physiological evaluation of the results of surgery in mitral stenosis was based upon reflected changes in the pulmonary circuit (Ferrer et al., 1955; Werkö et al., 1953; Janton et al., 1952). With the availability of direct pressure-flow measurements across the mitral valve, it was hoped that a more accurate assessment of the changes could be made, and a comparison of results based on these measurements with those previously derived from observed changes in the pulmonary circulation could be made.

The present study indicates that an accurate appraisal of the changes in the functional orifice size following mitral valvotomy requires a knowledge of both pressure gradient and flow across the valve. Changes in pressure gradient alone at the time of surgery as advocated by some workers (Moscovitz et al., 1955) are considered inadequate. From the data obtained, it can be seen that different interpretations become necessary when flow is known in patients with similar changes in pressure gradient. For example, a fall in pressure gradient signifying functional improvement can be appreciated in Case 1 who showed a large increase in flow as well. A fall in pressure gradient alone is misleading in Case 15 who had a decrease in mitral valve flow and little change in functional orifice size.

A comparison of Cases 10 and 13 shows that failure of the ventricular filling gradient to change following surgery does not always signify that the functional orifice was unchanged. Although Case 13 showed little change in gradient or flow and thus no change in valve area, Case 10 showed an increase in flow and area despite the small change in gradient.

In general, an unequivocally good response is indicated by a significant increase in flow accompanied by a significant fall in the pressure gradient. In such patients the functional valve area is always increased and generally the pressure in the left atrium is reduced. An increase in flow with no appreciable change in the pressure gradient may reflect functional improvement: evaluation of the surgical results is, however, difficult in such cases.

Patients who show little or no change in flow, gradient, and area represent a poor surgical result with little relief in the obstruction. One (Case 13) of the sixteen patients was classified this way. At surgery, the mitral orifice, finger-tip in size, was reported as increased to admit two fingers. A 
second (Case 12) showed no change in gradient: the flow was not obtained before operation and was low afterwards; the mitral valve area was still considered inadequate; and the valve was finger-tip size before and a loose-finger size afterwards.

When a decrease in mitral valve flow occurs after operation, the results of surgery again are difficult to assess. Fall in flow may be due to a difference in the basal state of the patient, cardiac failure, production of mitral regurgitation, or inadequate relief of the obstruction.

The height of the pulmonary artery pressure and in particular the presence of pulmonary hypertension has been used as a measure of the severity of the disease, and a major indication for surgery (Baronofsky, 1953; Werkö et al., 1953; Ferrer et al., 1955). The present study discloses, however, that widely varying degrees of pulmonary artery pressure may be found with the same valve area or level of pressure gradient. When the degree of mitral obstruction and the pulmonary vascular resistance are constant, the pulmonary artery pressure varies with flow (Goldberg et al., 1955). On the other hand, when the flow and mitral obstruction are constant, the level of pulmonary artery pressure varies with the degree of pulmonary vascular resistance. In the present group of patients, significant mitral obstruction was accompanied by normal, as well as severely raised pulmonary artery pressures. Although Case 1, one of the three patients with normal pressures in the pulmonary circuit, had minimal symptoms, Cases 2 and 11 complained of dyspnœa and fatigue and required digitalis therapy. Case 2 gave a history of transient atrial fibrillation and acute pulmonary œdema during pregnancy and Case 11 had a history of palpitation and congestive heart failure. The presence of pulmonary hypertension may not be the sole determining factor of the severity of disease or of the need for surgery in some cases when direct measurements of gradient and flow across the valve are known.

Evaluation of the changes in the pulmonary artery pressure following valvotomy, again necessitates the measurement of flow as well as pressure gradient. For example, Case 5, who had

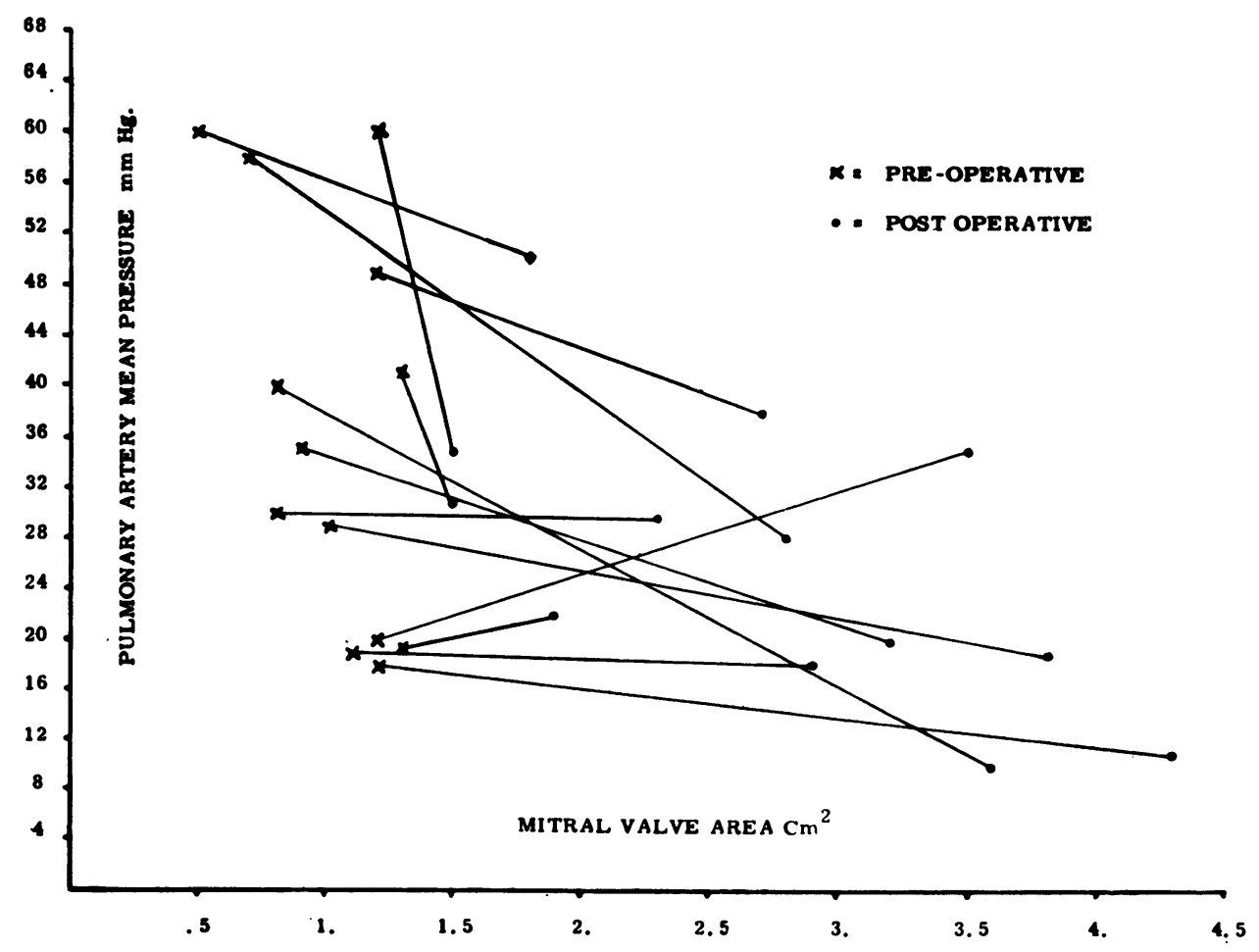

Fig. 2.-Relationship between the pulmonary artery pressure and mitral valve area before and after mitral valvotomy. 
no change in the pulmonary artery pressure, showed an increase in mitral valve flow accompanied by a significant fall in ventricular filling pressure gradient and was considered to demonstrate physiological improvement following surgery that was not reflected by the pulmonary circulation. The frequently reported patient, who shows subjective and clinical improvement with little or no change in the data obtained by right heart catheterization, namely, the pulmonary artery pressure, may have to be re-investigated with this in mind.

A fall in the pulmonary artery pressure, considered alone, may be misleading also. This result in Case 15 may be explained entirely by the fall in flow, the mitral valve area increasing only slightly, and pulmonary resistance remaining normal. In other patients, the decrease in pulmonary artery pressure is not proportional to the degree of improvement as judged by changes in the pressure gradient and mitral valve flow.

In general, it may be seen that the pulmonary circuit does not always reflect the changes in the dynamics at the mitral valve. Although in many cases, relief of obstruction at the mitral valve is accompanied by a fall in the pulmonary artery pressure, the latter may change little following an adequate mitral valvotomy (Fig. 2). The persistence of pulmonary hypertension may be attributed to (1) increased pulmonary vascular resistance due to vascular changes and (2) an increase in flow relative to a restricted capacity of the pulmonary bed. On the other hand, a fall in pulmonary artery pressure may be explained entirely by a decrease in flow when the degree of mitral obstruction is affected little by surgery.

The pressure in the left atrium is a function of the degree of mitral obstruction and the magnitude of mitral valve flow. Although the elasticity factors of the atrium are of great importance in the presence of mitral obstruction, an adequate increase in the valve area is accompanied by a fall in the atrial pressure in most patients (Fig. 3), even in the presence of large increases in flow. Changes

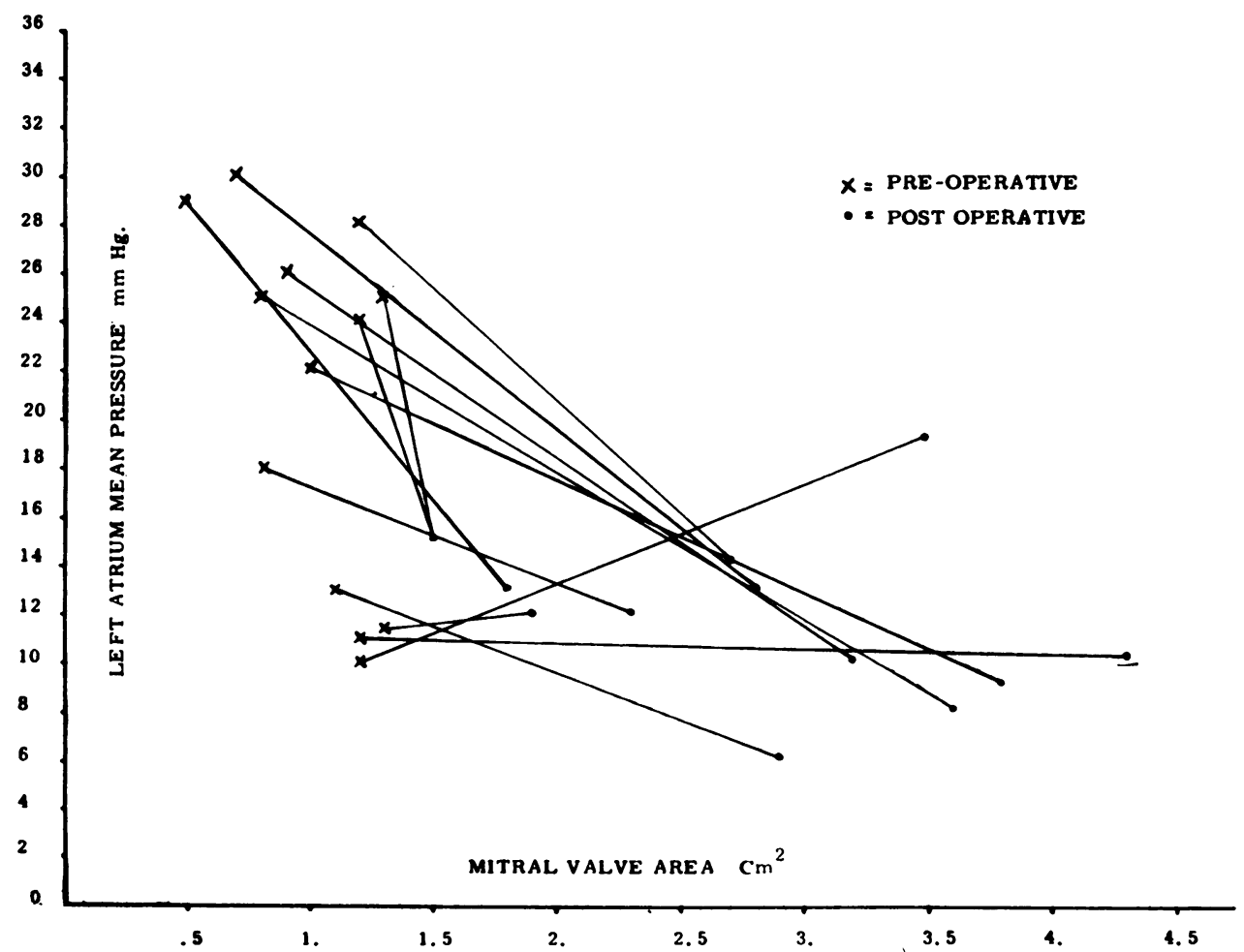

FIG. 3.-Relationship between the left atrial pressure and mitral valve area before and after mitral valvotomy. 
in the left atrial pressure more closely parallel improvement following mitral valvotomy than do changes in the pulmonary artery pressure (Fig. 2 and 3 ).

Although a fall in left atrial pressure accompanying a fall in the ventricular pressure gradient is the usual response following relief of obstruction, a rise of the diastolic pressure in the left ventricle, as a result of better filling after operation, may account for a fall in gradient, e.g. Cases 1 and 14, in which the left atrial pressure remains unchanged. In these patients the changes in the left atrial pressure cannot be employed as a measure of improvement. Changes in left atrial pressure tracings in patients following surgery are of some interest. As one would expect, the $a$ waves were much smaller in height in those patients who were classified as improved. The $v$ wave becomes more prominent following surgery, suggesting relief of obstruction with rapid filling of the left ventricle. The pulmonary venous capillary pressure paralleled the changes in the left atrial pressures.

As previously established, the left ventricular filling period in mitral stenosis frequently includes a portion of the isometric contraction and relaxation phases of the cardiac cycle, and thus exceeds the limits of diastole (Moscovitz et al., 1955). The changes in the ventricular filling period following mitral valvotomy are of interest. In patients with similar heart rates before and after surgery, a decrease in the ventricular filling period accompanied by a large increase in mitral valve flow is suggestive of relief of the obstruction. These patients had an excellent response to surgery based on the previously discussed criteria.

Since a decrease in the ventricular filling period accompanied by an increase in heart rate may be expected normally, such a change is difficult to assess. However, in patients with significant mitral valve obstruction, such a response would be accompanied probably by a fall in the mitral valve flow and/or a rise in ventricular filling pressure gradient and left atrial pressure. The decrease in the filling period in patients in whom there occurred both an increase in the mitral valve flow and a fall in the pressure gradient after operation would therefore seem to be significant despite an increased heart rate.

A decrease in heart rate results in a lengthening of the ventricular filling period. When the ventricular filling period was unchanged or decreased in the presence of a slower heart rate, and the response to surgery was otherwise considered good, this result would suggest that the filling period at a faster heart rate before operation was abnormally prolonged.

The changes in mitral valve area following surgery showed a good correlation with other findings in most instances. When the area was significantly increased, the mitral valve flow was always much increased and the left atrial pressure generally decreased. The pulmonary artery pressure generally fell or remained normal, but did not reflect the significant increase in area in all cases. In those patients with only slight increase in area, there were variable responses of mitral valve flow and left atrial and pulmonary artery pressures.

Mitral valve area in this group of patients was calculated both by the original Gorlin and the modified formulæ described above. A comparison of these areas shown in Table II reveals a number of discrepancies. Analysis of the values used in both formulæ reveals differences in both the ventricular filling period and, hence, mitral valve flow, and in the left atrial-left ventricular filling pressure gradient. The flows and areas are smaller as calculated by the original formula. The above discrepancies appear to be more striking after operation.

The "diastolic" filling period is consistently longer when obtained from the brachialartery pressure than directly from the left atrial and left ventricular pressure tracings. With the raised left atrial pressure before operation, this difference is frequently not striking and, hence, the mitral valve flows and areas do not differ significantly when calculated by either method. After operation, however, with the decrease in the left atrial pressure, the difference in the ventricular filling periods may be appreciable. In Cases 1 and 3 the ventricular filling periods obtained from the brachial artery tracings actually increase while they decrease when obtained directly from the left heart tracings. Hence, in these cases the discrepancy in mitral valve flows and areas may be considerable.

Frequently, the pressure gradient as calculated by the original Gorlin formula is larger than that measured directly from the pressure tracings. However, this is not too serious a difference 
TABLE II

Mitral Valve Area Before and After Mitral Valvotomy

\begin{tabular}{|c|c|c|c|c|c|c|c|}
\hline Patient & $\begin{array}{l}\text { Modified } \\
\text { formula }\end{array}$ & $\begin{array}{l}\text { Original } \\
\text { formula }\end{array}$ & $\begin{array}{l}\text { Surgeon's } \\
\text { estimate* }\end{array}$ & Patient & $\begin{array}{l}\text { Modified } \\
\text { formula }\end{array}$ & $\begin{array}{l}\text { Original } \\
\text { formula }\end{array}$ & $\begin{array}{l}\text { Surgeon's } \\
\text { estimate* }\end{array}$ \\
\hline \multirow{2}{*}{$\begin{array}{l}\text { Before } \\
\text { After }\end{array}$} & $1 \cdot 2$ & 1.4 & Tight $\mathrm{f}$ & \multirow{2}{*}{$9 \begin{array}{l}\text { Before } \\
\text { After }\end{array}$} & $1 \cdot 2$ & 0.5 & Less than $f$ tip \\
\hline & $4 \cdot 3$ & $2 \cdot 1$ & $2 \mathrm{f}$ & & $2 \cdot 9$ & - & $1 \frac{3}{4} \mathrm{f}$ \\
\hline \multirow{2}{*}{$2 \begin{array}{l}\text { Before } \\
\text { After }\end{array}$} & $1 \cdot 1$ & 1.5 & f tip & \multirow{2}{*}{$10 \begin{array}{l}\text { Before } \\
\text { After }\end{array}$} & $1 \cdot 2$ & 1.0 & f tip \\
\hline & $2 \cdot 9$ & $2 \cdot 9$ & $1 \frac{3}{4} \mathrm{f}$ & & $3 \cdot 5$ & $2 \cdot 1$ & $1 \frac{3}{4} \mathrm{f}$ \\
\hline \multirow{2}{*}{$\begin{array}{l}\text { Before } \\
\text { After }\end{array}$} & $1 \cdot 0$ & $0 \cdot 8$ & f tip & \multirow{2}{*}{ 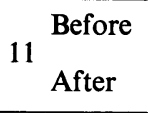 } & $1 \cdot 3$ & 0.5 & Less than $f$ tip \\
\hline & $3 \cdot 8$ & $2 \cdot 4$ & $2 \mathrm{f}$ & & 1.9 & $1 \cdot 0$ & $2 f$ \\
\hline \multirow{2}{*}{$4 \begin{array}{l}\text { Before } \\
\text { After }\end{array}$} & 0.9 & 0.6 & f tip & \multirow{2}{*}{$12 \begin{array}{l}\text { Before } \\
\text { After }\end{array}$} & - & - & f tip \\
\hline & $3 \cdot 2$ & $1 \cdot 7$ & $2 \mathrm{f}$ & & 0.7 & 0.4 & 1 loose $\mathrm{f}$ \\
\hline \multirow{2}{*}{$5 \begin{array}{l}\text { Before } \\
\text { After }\end{array}$} & $0 \cdot 8$ & 0.6 & Tight f tip & \multirow{2}{*}{$13 \begin{array}{l}\text { Before } \\
\text { After }\end{array}$} & $1 \cdot 2$ & - & f tip \\
\hline & $2 \cdot 3$ & $1 \cdot 3$ & $1 \frac{3}{4} \mathrm{f}$ & & $1 \cdot 5$ & $0 \cdot 3$ & $1 \frac{3}{4} \mathrm{f}$ \\
\hline \multirow{2}{*}{$\begin{array}{l}\text { Before } \\
\text { After }\end{array}$} & $0 \cdot 7$ & 0.7 & Tight $\mathrm{f}$ tip & \multirow{2}{*}{$14 \begin{array}{l}\text { Before } \\
\text { After }\end{array}$} & - & - & f tip \\
\hline & $2 \cdot 8$ & - & $1 \frac{1}{2} \mathrm{f}$ & & $3 \cdot 5$ & $2 \cdot 3$ & $1 \frac{3}{4} \mathrm{f}$ \\
\hline \multirow{2}{*}{$\begin{array}{l}{ }_{7} \text { Before } \\
\text { After }\end{array}$} & 0.4 & $0 \cdot 3$ & Less than $\mathrm{f}$ tip & \multirow{2}{*}{$15 \begin{array}{l}\text { Before } \\
\text { After }\end{array}$} & $1 \cdot 3$ & $1 \cdot 2$ & Tight $\mathrm{f}$ \\
\hline & $1 \cdot 8$ & $1 \cdot 1$ & $1 \frac{1}{2}-1 \frac{3}{4} \mathrm{f}$ & & $1 \cdot 5$ & - & $1 \frac{1}{2} \mathrm{f}$ \\
\hline \multirow{2}{*}{${ }_{8} \begin{array}{l}\text { Before } \\
\text { After }\end{array}$} & $0 \cdot 8$ & - & f tip & \multirow{2}{*}{$16 \begin{array}{l}\text { Before } \\
\text { After }\end{array}$} & - & - & f tip \\
\hline & $3 \cdot 6$ & $\dagger$ & $1 \frac{3}{4} \mathrm{f}$ & & $2 \cdot 0$ & $\dagger$ & $2 \mathrm{f}$ \\
\hline
\end{tabular}

* Surgeon's estimate-Dr. C. P. Bailey, in fingers (f).

$\dagger$ Pulmonary capillary pressure less than $5 \mathrm{~mm}$. Hg.

since the square root of the gradient is employed in the calculations. Occasionally the pulmonary venous capillary pressure cannot be obtained due to technical difficulties, or may be less than $5 \mathrm{~mm}$. $\mathrm{Hg}$, as occasionally is observed following mitral valvotomy (Cases 8 and 16): the mitral valve areas cannot then be calculated by the Gorlin method.

A combination of the above factors in any individual case produces varying differences in the mitral valve area calculated by both methods, but in general those calculated by the Gorlin formula are smaller. This is of special interest in the evaluation of the surgical results since, in many cases, areas after operation calculated by the original formula may still appear inadequate and may actually suggest significant residual stenosis, but larger values are obtained in these patients when employing the direct left heart measurements.

This series is too small to predict the response to valvotomy from analysis of the physiological data before operation. Nevertheless, there was little difference in the hæmodynamic pattern before operation in those subjects exhibiting excellent, questionable, or poor responses. However, two patients who showed a poor response of gradient and flow afterwards had small flows and gradients before. It is of interest to note that the pulmonary artery pressure was much raised in one and within normal limits in the other. Valvular pathology and surgical technique undoubtedly play important roles in the final result.

The presence of myocardial insufficiency as the predominant abnormality is an important consideration in assessing the surgical results. However, in the absence of clinical failure, evaluation 
of this factor is difficult, and even the presence of failure may be due to predominant mitral obstruction. The absence of pulmonary hypertension, as suggested by some workers (Ferrer et al., 1955), does not exclude mitral obstruction as shown by combined heart catheterization, and normal pressure may exist in the presence of significant mitral stenosis. These patients may respond with an excellent surgical and physiological result, as shown by the above data.

From the present study, it can be seen that data obtained by right heart catheterization alone are frequently inadequate or even misleading in an individual case: estimation of the degree of stenosis cannot always be made on the basis of indirect measurements of the pulmonary circulation. The demonstration of a pressure gradient across the mitral valve establishes unquestionably the diagnosis of mitral stenosis. The simultaneous measurement of mitral valve flow and pressure gradient by combined heart catheterization not only permits estimation of the severity of the obstruction, but also allows for a more accurate estimation of the degree of improvement following mitral valvotomy.

\section{SUMmary}

Sixteen patients were studied before and after mitral valvotomy by combined heart catheterization. Measurement of the ventricular filling pressure gradient alone is inadequate in assessing the results of valvotomy since the changes in flow significantly influence the hæmodynamics, and may lead to erroneous interpretations.

The response is considered excellent when there is a significant increase in the mitral valve flow accompanied by a significant fall in the left ventricular filling pressure gradient. Those patients who show an increase in flow with little change in gradient need further evaluation. Those who are considered to have done poorly revealed little change in either.

The pulmonary artery pressure in general falls when there is a good response in pressure gradient and in mitral valve flow and area. However, the changes are not always parallel. The pulmonary artery pressure may change little in spite of a fall in pressure gradient and an increase in flow and functional valve area. Hence, in the individual patient, a knowledge of both flow and pressure gradient is essential in judging the significance of the changes in the pulmonary artery pressure.

The left atrial pressure generally falls with an adequate increase in mitral valve area. Areas calculated by the original Gorlin formula frequently indicate residual mitral stenosis after operation while the modified formula more adequately reflects the increase in functional orifice size.

Analysis of data before operation in this small series reveals little information as yet upon which to predict the result of the operation. A normal resting pulmonary artery pressure may be found in the presence of a significant degree of stenosis and a good surgical result may be obtained in these patients.

\section{REFERENCES}

Baronfsky, I. D. (1953). Surgery, 34, 347.

Biörk, V. O., Malstrom, G., and Uggla, L. G. (1953). Ann. Surg., 138, 718.

Bougas, J., Musser, B. G., and Goldberg, H. (1956). Amer. Heart J., 52, 359.

Carlotti, J., Joly, F., Sicot, J. R., and Voci, G. (1953). La Semaine Hôp., Paris, 29, 2079.

Ferrer, M. I., Harvey, R. M., Wylie, R. H., Himmelstein, A., Lambert, A., Kuschner, M., Cournand, A., and Richards, D. W. (1955). Circulation, 12, 7.

Goldberg, H., Dickens, J., Raber, G., and Hayes, E., Jr. (1955). Circulation, 12, 713.

T. Smith, R. C., Villaca, L., Woldow, A., and Raber, G. (1956). Fed. Proc., 15, 77.

Gorlin, R., and Gorlin, S. G. (1951). Amer. Heart J., 41, 1 .

Janton, O. H., Glover, R. P., O'Neill, T. J. E., Gregory, J. E., and Froio, G. F. (1952). Circulation, 6, 321.

Jordan, P., and Hellems, H. K. (1952). Surg., Gynec., Obst., 95, 689.

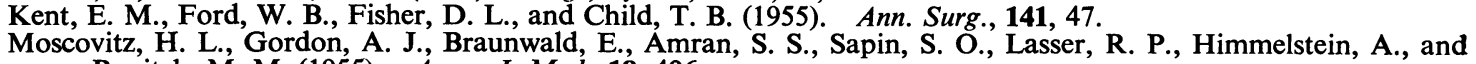
Ravitch, M. M. (1955). Amer. J. Med., 18, 406.

Musser, B. G., Bougas, J., and Goldberg, H. (1956). Amer. Heart J., 52, 567.

Van Slyke, D.' D., and Neill, J. M. (1924). J. Biol. Chem., 61, 523.

Werkö, L., Biörk, G., Crafoord, C., Wulff, H., Krook, H., and Eliasch, H. (1953). Amer. Heart J., 45, 477. 